\title{
The Role of NSAIDs in Breast Cancer Prevention and Relapse: Current Evidence and Future Perspectives
}

\author{
Demetrios Moris $^{a} \quad$ Michalis Kontos $^{a}$ Eleftherios Spartalis ${ }^{a} \quad$ Ian S. Fentiman ${ }^{b}$ \\ a 1st Department of Surgery, University of Athens, 'Laikon' General Hospital, Athens, Greece; \\ ${ }^{\mathrm{b}}$ Research Oncology, Bermondsey Wing, Guy's Hospital, London, United Kingdom
}

\section{Keywords}

NSAIDs · Breast cancer - Aspirin · Hormone receptors · Prevention

\section{Summary}

Aspirin and other non-steroidal anti-inflammatory drugs (NSAIDs) have received considerable interest as potential chemopreventive agents. The aim of this review is to summarize the accumulated knowledge on the effect of NSAIDs on breast cancer incidence and natural history, and the underlying pathophysiology. NSAIDs mainly block inflammation by inhibiting cyclooxygenase enzymes, leading to lower prostaglandin synthesis. The latter has been reported to affect breast cancer risk through hormonal and inflammation-related pathways. Intensity, dose, frequency, duration, and timing of administration may also be significant. There is currently enough evidence to support a role of NSAIDs in breast cancer prevention and relapse, which deserves further large-scale experimental and clinical investigation.

(C) 2016 S. Karger GmbH, Freiburg

\section{Introduction}

Breast cancer is the most common non-cutaneous cancer and the second leading cause of cancer-related death among women in the United States [1]. It is estimated that 1 in 8 women will develop breast cancer over her lifetime [2]. The rate of breast cancer inci- dence has remained relatively unchanged in the past 30 years, and worldwide more than $40 \%$ of breast cancer cases continue to result in death $[1,3]$.

Aspirin and other non-steroidal anti-inflammatory drugs (NSAIDs) have received considerable interest as potential chemopreventive agents [4-6]. NSAIDs are inversely associated with the risk of colorectal and other gastrointestinal cancers (e.g. stomach and esophageal cancer) $[5,7,8]$. The protective effect of NSAIDs against these types of cancer has prompted studies on breast cancer prevention by NSAIDs. Results from epidemiological studies of breast cancer, however, are conflicting [9], despite many meta-analyses having indicated a chemopreventive effect of aspirin or NSAIDs against the disease $[8,10-13]$. In contrast, some cohort and casecontrol studies have reported no reduced risk of breast cancer from use of either aspirin [14-22] or non-aspirin NSAIDs [14-17, 23, 24].

The conflicting evidence may be attributable to a combination of factors including poor precision and chance variation, low response rates with possible selection bias, short follow-up time, limited exposure data, or failure to distinguish between different NSAIDs subclasses [25].

The aim of this review is to give a conceptual description of the effect of NSAIDs on breast cancer incidence and natural history, and the underlying pathophysiology.

\section{Methods}

The MEDLINE/PubMed database was searched for publications with the medical subject heading 'breast' and keywords 'aspirin' or 'NSAIDs' or 'nonsteroidal' or 'anti-inflammatory'. Our selection criteria were English language, oncological relevance (publications irrelevant to breast cancer, e.g. breast abscess treatment, were excluded), timeframe of the last 20 years (1996-2016), and availability of full-text articles. We included 60 articles. Our aim was to review the effect of NSAIDs on the natural history, prevention, recurrence, and pathophysiology of breast cancer.

\section{KARGER}

Fax +497614520714
๑๑ 2016 S. Karger GmbH, Freiburg
Eleftherios Spartalis, MD, MSc, PhD

1st Department of Surgery, University of Athens

'Laikon' General Hospital

Agiou Thoma 17, 11527 Athens, Greece

eleftherios.spartalis@gmail.com 


\section{Results}

\section{Pathophysiology}

NSAIDs mainly block inflammation by inhibiting cyclooxygenase (COX) enzymes, leading to lower prostaglandin synthesis. Lowered levels of prostaglandins also inhibit aromatase activity, which in turn leads to lower serum estrogen levels $[14,26]$ and consequently to a decreased incidence of hormone receptor-positive tumors. The PI3K/AKT/IKK and the mitogen-activated protein (MAP) kinase pathways are involved in collagen- and prostaglandin E2 (PGE2)-induced aromatase expression. Additionally, collagen and PGE2-induced signaling pathways may crosstalk in regulating aromatase expression [26]. Furthermore, PGE2 causes a significant decrease in p53 transcript and nuclear protein expression, as well as phosphorylation at Ser15, in primary human breast adipose stem cells. Stabilization of p53 leads to a significant decrease in PGE2-stimulated aromatase mRNA expression and activity.

COX-2 concentrations are undetectable in normal breast tissue but are overexpressed $[27,28]$ in breast tumors by approximately $40 \%$, and in ductal carcinoma in situ by as much as $80 \%$ [29].

COX-2 expression has been associated with prostaglandin synthesis [30,31]. PGE2 is considered a powerful mitogen and potential chemopreventive target [4]. PGE2 has been shown to induce aromatase expression and de novo estrogen synthesis in breast epithelia and stromal cells in vitro; introduction of NSAIDs reduces estrogen levels in a dose-dependent manner [32] (supplementary fig. 1, www.karger.com/?DOI=452315).

Because inflammation is closely associated with tumorigenesis, COX-2 has been shown to be overexpressed in precancerous and malignant lesions [33-35]. Its inhibition and the suppression of prostaglandin synthesis is widely accepted as the primary mechanism of the anticancer activity of NSAIDs.

However, some studies have concluded that a rather COXindependent mechanism may either contribute to or be exclusively responsible for the chemopreventive activity of NSAIDs [34-36].

There is limited evidence that COX-2 expression is correlated with estrogen receptor (ER), progesterone receptor (PR), human epidermal growth factor receptor 2 (HER2), and p53 expression in breast tumors [37, 38]. Findings of in vitro studies among human invasive breast cancer cells suggest that HER2 oncogene activation regulates COX-2 expression in breast cancer $[38,39]$, inducing a positive feedback loop in which PGE2 in turn further induces HER2 expression [40]. NSAIDs have been shown to reduce HER2 expression [40]. P53 may also be associated with COX-2 expression in vitro [41], and animal models of breast cancer give limited evidence that p53 expression is associated with COX-2 expression [42].

Additionally, it is shown that the SDF-1/CXCR4 axis is a main regulator of normal and tumor cell trafficking. Thus, it is reasonable to hypothesize that NSAIDs may interfere with SDF1 levels via the pathway COX-2 PGE SDF-1, resulting in an impairment of processes underlying metastasis development [43].
Another possible explanation involves inflammation-induced platelet degranulation, with release of angiogenesis-regulating factors, including vascular endothelial growth factor, which can be countered by ketorolac [43] (supplementary fig. 2, www.karger. $\mathrm{com} /$ ?DOI=452315).

\section{Aspirin and Breast Cancer Risk}

Compared with women who never used aspirin, women regularly consuming aspirin had an about $20 \%$ lower risk of breast cancer after adjusting for major breast cancer risk factors [2]. Higher frequency of use was associated with a lower risk of breast cancer and this was statistically very significant [2]. Furthermore, women who used aspirin $>10$ days/month across their adult lifetime were at a reduced risk of breast cancer, although this finding was of borderline statistical significance (odds ratio (OR) 0.69, 95\% confidence interval (CI) 0.49-1.00) [44].

As far as the receptor status of the tumor is concerned, inverse associations for aspirin use were observed for ER+ (relative risk (RR) $0.77,95 \%$ CI 0.67-0.89), ER- (RR 0.78, 95\% CI 0.56-1.08), PR+ (RR 0.79, 95\% CI 0.68-0.92), and PR- (RR 0.73, 95\% CI 0.56$0.95)$ breast cancers [2]. Women who used aspirin regularly throughout their adult life had a similar reduction in both ER+ and ER- breast cancers [31].

Compared to non-use, aspirin use was associated with reduced risk for both HER2+ (OR 0.84, 95\% CI 0.52-1.36) and HER2- breast cancers (OR 0.91, 95\% CI 0.76-1.09) ( $\mathrm{p}=0.76$ ) [31]. Additionally, no clear differences in the associations of aspirin use with breast cancer characterized by combinations of ER, PR, and HER2 were observed [31]. Furthermore, no significant differences in risk by p53 status associated with aspirin use were noticed [31]. Lifetime aspirin use was also similarly associated with significant reductions in the risk of HER2- (OR 0.60, 95\% CI 0.38-0.95; p = 0.04) and p53(OR 0.56, 95\% CI 0.33-0.95; $\mathrm{p}=0.02$ ) breast cancers; however, the point estimates were not statistically different compared to those for HER2+ $(\mathrm{p}=0.20)$ or $\mathrm{p} 53+$ tumors $(\mathrm{p}=0.48)$ [31].

As far as the histological type of the tumor is concerned, regular lifetime aspirin use was associated with a $41 \%$ reduction in risk of luminal A breast cancer (OR 0.59, 95\% CI 0.36-0.97; p = 0.05) and a statistically non-significant $48 \%$ reduction in risk of triple-negative breast cancer (OR 0.52, 95\% CI 0.18-1.54; $\mathrm{p}=0.26$ ) [31]. There was no clear association of lifetime aspirin use with either the luminal B or the HER2-expressing phenotypes.

The multivariable incidence rate ratio (mIRR) for the association between current aspirin use at baseline and breast cancer incidence was 0.90 ( $95 \%$ CI $0.75-1.07$ ); the $\mathrm{mIRR}$ for $\geq 5$ years of use was 0.78 (95\% CI 0.58-1.05; p for trend $=0.15)$ [28]. This study showed no association between breast cancer and duration of current or past aspirin use ( $\mathrm{p}=0.79$ and 0.80 , respectively) in the fully adjusted models [22]. The risk estimates for women using aspirin varied little by current or past use (for 6 years of use, HR $1 / 41.05,95 \%$ CI 0.88-1.25 and HR $1 / 4$ 1.04, 95\% CI 0.84-1.27, respectively) [22].

Gill et al. [22] showed that aspirin use was not associated with breast cancer for any of the ethnic groups, nor was total NSAID use. 
For each of the decades of life, Brasky et al. [44] observed a mostly uniform reduction in breast cancer risk associated with a reported frequency of use of $\geq 2$ days per month compared to nonusers [44]. However, aspirin during the 7th decade of life was associated with the greatest reduction in breast cancer risk (OR 0.73 , 95\% CI 0.51-1.03) [44].

\section{Non-Aspirin NSAIDs and Breast Cancer Risk}

There have been conflicting reports regarding the association between non-aspirin NSAIDs and breast cancer risk.

In a study by Bardia et al. [2], there was no association between the use of non-aspirin NSAIDs with the risk of breast cancer, overall or by ER or PR status, with the possible exception of a positive trend of non-aspirin NSAID use and risk of PR- tumors ( $\mathrm{p}=$ 0.051). On the other hand, another study showed that NSAIDs significantly reduce the risk of de novo disease with no apparent discrimination between ER+ or ER- types [45].

To add to the confusion, Brasky et al. [31] concluded that recent ibuprofen users had a statistically significant increased risk of $\mathrm{ER}+/ \mathrm{PR}+(\mathrm{OR} 1.33,95 \%$ CI 1.09-1.62) but not ER+/PR-, ER-/ $\mathrm{PR}+$, or ER-/PR- breast cancer compared to non-users. This study, however, has several important limitations. According to the authors', the classification of subtypes based on ER, PR, and HER2 was a surrogate for a more comprehensive nomenclature determined by tumor marker expression; therefore, the subtypes defined in this study, particularly the differences between luminal A and B tumors, may be misclassified. Because fluorescence in situ hybridization was not performed to validate tumors with an equivocal (i.e. 2+) HER2 score, and the agreement between immunohistochemistry and medical records was good but not excellent, misclassification of HER2 status is possible. As far as the HER2 status is concerned, use of ibuprofen was suggestive of a $50 \%$ reduction in the risk of HER2-expressing tumors, although not statistically significant [31]. Besides, ibuprofen was not associated with the risk of triple-negative breast cancer (OR 0.99, 95\% CI $0.68-1.45)$ [31].

Use of ibuprofen in the previous year was associated with a statistically significant $27 \%$ increased risk of HER2- breast cancers (OR 1.27, 95\% CI 1.05-1.53) and was not associated with HER2+ breast cancers (OR 0.83, 95\% CI 0.51-1.35) [31]. Compared to non-use, categories of ibuprofen frequency and intensity were associated with elevated risks of HER2- tumors [31].

Recent ibuprofen use was not associated with p53+ tumors, while it was positively associated with risk of p53- tumors (OR $1.28,95 \%$ CI 1.04-1.57) [31]. However, point estimates were not statistically different $(\mathrm{p}=0.11)$ [31].

As far as the histological subtypes of the tumor are concerned, use of ibuprofen was associated with an increased risk of luminal A (OR 1.34, 95\% CI 1.09-1.65) and luminal B (OR 1.41, 95\% CI 0.692.87) breast cancer [31].

With regard to current and past use of non-aspirin NSAIDs, an association was found between duration of current use of other NSAIDs and breast cancer $(\mathrm{p}=0.01)$ but not for duration of past use [22]. Current other NSAIDs for 6 or more years decreased the risk of breast cancer by $30 \%$ (95\% CI $0.51-0.95)$ [22]. A test of interaction between duration and an indicator variable of current/ past use of other NSAIDs suggested a possible interaction ( $p$ interaction $=0.07$ ), signifying that total duration of current and past use should not be combined [22].

With regard to selective COX-2 inhibitors, no reduced risk of breast cancer was associated with ever versus never/rare use. The same study also found no correlation between breast cancer risk and non-selective non-aspirin NSAIDs or aspirin (OR 0.98, 95\% CI 0.90-1.07) [25]. The timing of non-selective non-aspirin NSAID or selective COX-2 inhibitor use did not influence breast cancer risk either [25].

As far as race is concerned, the protective association of current duration of other NSAID use with breast cancer was found for African- American and Caucasian women only ( $\mathrm{p}=0.02$ for both ethnic groups) [22].

\section{NSAIDs Combination and Breast Cancer Risk}

In an analysis of combined use of aspirin and other NSAIDs, lower risk of breast cancer was observed for aspirin use only (RR 0.82 ; 95\% CI 0.70-0.95) or use of both (RR 0.77; 95\% CI 0.65-0.91), but not for use of other non-aspirin NSAIDs only. This pattern was fairly consistent for all hormone receptor statuses [2]. Recent use of ibuprofen and acetaminophen was not associated with breast cancer risk changes [44].

Selective COX-2 inhibitor use was not associated with breast cancer occurrence among individuals with (OR 1.12, 95\% CI 0.861.44 ) or without (OR $1.07,95 \%$ CI $0.98-1.17$ ) a history of NSAID use before beginning selective COX-2 inhibitor use [25]. There was no evidence of a reduced risk of breast cancer among women who used selective COX-2 inhibitors only (ever use OR 1.09, 95\% CI $0.98-1.22$; recent use OR $0.99,95 \%$ CI $0.80-1.23$; former use OR $1.13,95 \%$ CI 1.00-1.29) [25].

\section{NSAIDs and Breast Cancer Recurrence}

Recent epidemiological studies have shown that NSAIDs can markedly reduce the risk of breast cancer recurrence in patients previously treated for ductal carcinoma in situ or invasive disease [46].

Careful analysis of breast cancer recurrences suggested a paradigm where early recurrences are induced by an angiogenic switch in avascular micrometastases and single cell activation [43]. Both events are suggested to be triggered by the surgical removal of the primary tumor. Results reported by Forget et al. [47] suggesting that the perioperative NSAID ketorolac significantly reduces early relapses may be explained in light of this model.

In this frame of analysis, ketorolac, an anti-inflammatory analgesic, was associated with significantly superior disease-free survival in the first few years after surgery [43]. Indeed, the survival in the ketorolac group showed a small bump in the first 10 months and then slowly rose until the 4th year when follow-up of this series ended [43]. After 24 months, the ketorolac group's hazard rate pattern was indistinguishable from the corresponding pattern for the no-ketorolac group [43]. 
Table 1. Summary of the effect of non-steroidal anti-inflammatory drugs (NSAIDs) on the natural history of breast cancer. E = Evidence according to the Oxford grading system, levels of evidence; $\mathrm{R}=$ recommendation by the authors according to the AGO recommendation system [61, 62]

\begin{tabular}{|c|c|c|c|c|c|}
\hline Drug & $\mathrm{BC}$ risk & $\mathrm{BC}$ recurrence & Receptor status & Histological type & Survival \\
\hline Aspirin (AS) & $\begin{array}{l}\text { women regularly } \\
\text { consuming AS had an } \\
\text { about } 20 \% \text { lower risk } \\
\text { of BC [2] (prospective } \\
\text { cohort study, 26,580 } \\
\text { postmenopausal } \\
\text { women, E: IB, R:+) }\end{array}$ & $\begin{array}{l}\text { AS was associated } \\
\text { with a decreased risk } \\
\text { of distant recurrence } \\
\text { [51-52] (prospective } \\
\text { study 27,426 women, } \\
\text { E: IB, R:+) }\end{array}$ & $\begin{array}{l}\text { i) women who used AS regu- } \\
\text { larly had a similar reduction in } \\
\text { both estrogen receptor (ER)+ } \\
\text { and ER- BC [31] (case study, } \\
1,170 \text { women, E: III, R:+/-) } \\
\text { ii) AS was associated with } \\
\text { reduced risks for both HER2+ } \\
\text { and HER2- BC [31] (case } \\
\text { study, 1,170 women, E: III, } \\
\text { R:+/-) }\end{array}$ & $\begin{array}{l}\text { AS was associated with a } \\
41 \% \text { reduction in risk of } \\
\text { luminal A BC and a } 48 \% \\
\text { reduction in risk of triple- } \\
\text { negative BC [31] } \\
\text { (case study, } 1,170 \text { women, } \\
\text { E: III, R:+/-) }\end{array}$ & $\begin{array}{l}\text { Nurses' Health Study } \\
\text { suggested a reduced risk } \\
\text { of BC mortality and all- } \\
\text { cause mortality for } \\
\text { women reporting AS } \\
\text { use after BC [51] } \\
\text { (prospective study } \\
27,426 \text { women, E: IB, } \\
\text { R:+) }\end{array}$ \\
\hline $\begin{array}{l}\text { Non-AS } \\
\text { NSAIDs }\end{array}$ & $\begin{array}{l}\text { no association be- } \\
\text { tween the use of non- } \\
\text { AS NSAIDs with the } \\
\text { risk of BC [2] } \\
\text { (prospective cohort } \\
\text { study, } 26,580 \text { post- } \\
\text { menopausal women, } \\
\text { E: IB, R:+) }\end{array}$ & $\begin{array}{l}\text { regular use of ibupro- } \\
\text { fen (IB) was associ- } \\
\text { ated with a statistically } \\
\text { significant decreased } \\
\text { risk of BC recurrence } \\
\text { [46] (prospective } \\
\text { study, 2,292 early- } \\
\text { stage BC survivors, E: } \\
\text { IIA, R:+) }\end{array}$ & $\begin{array}{l}\text { i) IB users had a statistically } \\
\text { significant increased risk of } \\
\text { ER+/progesterone receptor } \\
\text { (PR)+, but not ER+/PR-, ER-/ } \\
\text { PR+, or ER-/PR- BC compared } \\
\text { to non-users [31] (case study, } \\
1,170 \text { women, E: III, R:+/-) } \\
\text { ii) IB was suggestive of a 50\% } \\
\text { reduction in the risk of HER2- } \\
\text { expressing tumors [31] (case } \\
\text { study, } 1,170 \text { women, E: III, } \\
\text { R:+/-) }\end{array}$ & $\begin{array}{l}\text { i) IB was not associated } \\
\text { with the risk of triple- } \\
\text { negative BC [31] (case } \\
\text { study, 1,170 women, E: } \\
\text { III, R:+/-) } \\
\text { ii) IB was associated with } \\
\text { an increased risks of lu- } \\
\text { minal A and luminal B } \\
\text { BC [31] (case study, 1,170 } \\
\text { women, E: III, R:+/-) }\end{array}$ & $\begin{array}{l}\text { Iowa Women's Health } \\
\text { Study showed that ever } \\
\text { use of any NSAID after } \\
\text { diagnosis was associated } \\
\text { with a statistically sig- } \\
\text { nificant reduction in } \\
\text { all-cause mortality and } \\
\text { a non-significant reduc- } \\
\text { tion in BC mortality } \\
\text { [50] (prospective study, } \\
591 \text { postmenopausal } \\
\text { women, E: IB, R:+) }\end{array}$ \\
\hline $\begin{array}{c}\text { Selective COX-2 } \\
\text { inhibitors }\end{array}$ & $\begin{array}{l}\text { no reduced risk of BC } \\
\text { associated with ever } \\
\text { vs. never/rare use [25] } \\
\text { (case study, } 8,195 \text { BC } \\
\text { cases, E: III, R:+/-) }\end{array}$ & $\begin{array}{l}\text { no statistically signifi- } \\
\text { cant effect on recur- } \\
\text { rence risk [46] (pro- } \\
\text { spective study, } 2,292 \\
\text { early-stage BC survi- } \\
\text { vors, E: IIA, R:+) }\end{array}$ & - & - & $\begin{array}{l}\text { no benefit [48] (case } \\
\text { study, } 1,024 \text { primary in- } \\
\text { vasive BC cases, E: III, } \\
\text { R:+/-) }\end{array}$ \\
\hline
\end{tabular}

Recently, regular use of ibuprofen was associated with a statistically significant decreased risk of breast cancer recurrence (RR 0.56, 95\% CI 0.32-0.98) [46]. Although use of other non-aspirin NSAIDs such as naproxen, sulindac, nabumetone, etodolac, meloxicam, and piroxicam had no statistically significant effect on recurrence risk (RR 0.52, 95\% CI 0.13-2.13), the combination of these NSAIDs with ibuprofen was associated with a significantly decreased risk of disease relapse (RR 0.56, 95\% CI 0.33-0.95). Finally, use of acetaminophen was not associated with risk of recurrence (RR 1.21, 95\% CI 0.73-2.00) [46].

The associations between NSAID use and risk of recurrence did not appear to vary by menopausal status, body mass index, hormone receptor status, cancer stage, or chemotherapy use [46].

\section{The Role of NSAIDs in Survival of Breast Cancer Patients}

Pre-diagnosis use of ibuprofen was associated with reduced allcause mortality in univariate analysis (HR 0.65, 95\% CI 0.48-0.89) and borderline significance after adjustment for potential confounders (HR 0.71, 95\% CI 0.50-1.00) [48]. However, none of the NSAIDs were associated with a reduction in breast cancer-specific mortality [48]. This was similar to a large study where post-diagnosis NSAID use was not associated with all-cause or breast cancer mortality in 3,058 breast cancer cases in Wisconsin [49].

In the Iowa Women's Health Study, ever use of any NSAID after diagnosis was associated with a statistically significant reduc- tion in all-cause mortality and a non-significant reduction in breast cancer mortality among 591 postmenopausal women with invasive breast cancer [50].

Additionally, data from the Nurses' Health Study suggested a reduced risk of breast cancer mortality and all-cause mortality for women reporting aspirin use after breast cancer [51]. Only during the 0-6 month period before the end of follow-up was the (at least) daily use of aspirin versus non-use associated with a decreased risk of death from breast cancer (HR 0.69, 95\% CI 0.56-0.86) [52]. However, in the same timeframe, those using aspirin less than daily had an increased risk of death from breast cancer (HR 1.43, 95\% CI 0.09-1.87) [52].

Table 1 summarizes the effects of NSAIDs on the natural history of breast cancer.

\section{Discussion}

Use of any NSAID was associated with reduced risk of breast cancer in a global analysis [12]. This association was stronger for case-control studies than for cohort studies. High intake of NSAIDs had no different effect compared to any intake with the RRs associated with reduced risk of breast cancer being comparable [12].

Regarding the effect of the timing of NSAID intake on breast cancer incidence, Sharpe et al. [53] investigated the association of 
breast cancer risk with any NSAID use 1-6 months, 7-12 months, 2-5 years, 6-10 years, and 11-15 years prior to cancer development. They found no clear benefit of NSAID use in all but the time period 2-5 years prior to diagnosis; however, the authors were unable to account for over-the-counter NSAID use [53].

Use of aspirin was associated with a reduced risk of breast cancer [12]. This relationship is consistent with most case-control [14, 54-57] and cohort studies [19, 58], despite a few exceptions [18, 20, $22,59]$. In a meta-analysis of 11 case-control and cohort studies, aspirin use was found to be associated with a $23 \%$ lower risk of breast cancer (95\% CI 0.69-0.86). Again, the association was stronger among case-control studies than cohort studies [12].

High intake did not increase the magnitude of the association [12]. Higher frequency ( $>4$ times/day) of aspirin use has also been associated with lower risk of breast cancer [13]. Furthermore, while some studies have reported that aspirin use $>5$ years is associated with lower risk of breast cancer [14, 54, 57], a recent meta-analysis of 26 case-control and cohort studies reported no association with duration of use [13].

Most studies have reported no difference in results based on hormone receptor status and aspirin administration [17, 20, 22, 57, $58]$, with the exception of 3 studies [14, 54, 56]. In the California Teachers Study cohort, there was an increased risk of ER-/PR- but not ER+/PR+ tumors with daily aspirin use [14]. Finally, the AARP Diet and Health Study cohort [19] found that the beneficial effect of Aspirin was stronger for ER+ tumors as compared to ER- tumors.

Use of ibuprofen has a yet undefined effect on breast cancer risk. This agent has been reported to be associated with increased risk of breast cancer in some prospective studies $[14,20,22,60]$, though the exact mechanism is not clear. On the other hand, ibuprofen was reported to reduce this risk in the meta-analysis by Takkouche et al. [12] (RR 0.79, 95\% CI 0.64-0.97). As with aspirin intake, high intake of ibuprofen did not increase the magnitude of the association [12].

It is currently unknown why aspirin and ibuprofen exert different chemopreventive effects. Aspirin has a longer plasma half-life (12 h) than ibuprofen $(2 \mathrm{~h})$, and it binds irreversibly to COX-2. It is not clear whether this would translate into a greater anticancer effect, especially as others have observed inverse associations with non-aspirin NSAIDs [12]. For this purpose, large prospective studies should be designed to evaluate the mechanisms behind the different effect that aspirin and non-aspirin NSAIDs have on tumor surveillance.

NSAIDs can markedly reduce the risk of breast cancer recurrence in patients previously treated for the disease [46]. This can be attributed to the suppression of the inflammatory process necessary to trigger the development of metastasis. Ketorolac and ibuprofen have both been reported to have a favorable effect on breast cancer survival, unlike acetaminophen which was not associated with risk of recurrence [43].

On the other hand, the diverse pharmacologic effects of NSAIDs, when combined with the relatively low probability that an individual with average risk will develop any single type of cancer over a lifetime, severely limit the tolerance for toxicity if aspirin or related drugs are to be administered prophylactically to large numbers of otherwise healthy people.

\section{Conclusion}

Aspirin and other non-aspirin NSAIDs have received considerable interest as potential breast cancer chemopreventive agents. The results of our present analysis lead to the conclusion that aspirin and possibly other NSAIDs seem to decrease the risk of breast cancer. Regarding breast cancer recurrence, ketorolac and ibuprofen may exert a protective effect. However, the role of this effect with regard to survival is marginal or equivocal.

It is clear that studies on the effect of NSAIDs on breast cancer risk frequently lead to contradictory results. It is not known whether these differences should be attributed to study design or to the difficulty of understanding the exact mechanisms of the influence of NSAIDs on the natural history of breast cancer.

We do believe that the role of NSAIDs in breast cancer deserves further experimental investigation and large-scale prospective randomized clinical trials.

\section{Online Supplementary Figures}

Supplementary Fig. 1. Flow chart.

Supplementary Fig. 2. Summary of the actions of NSAIDS at a cellular level. Green arrow: induction. Red arrow: inhibition.

To access the online supplementary figures, please refer to www.karger. $\mathrm{com} /$ ?DOI=452315.

\section{Disclosure Statement}

The authors have no potential conflicts of interest. This research received no specific grant from any funding agency in the public, commercial, or notfor-profit sector.

\section{References}

1 Jemal A, Siegel R, Ward E, et al.: Cancer statistics, 2009. CA Cancer J Clin 2009;59:225-249.

$\checkmark 2$ Bardia A, Olson JE, Vachon CM, et al.: Effect of aspirin and other NSAIDs on postmenopausal breast cancer incidence by hormone receptor status: results from a prospective cohort study. Breast Cancer Res Treat 2011;126:149-155.
Virnig BA, Tuttle TM, Shamliyan T, Kane RL: Ductal carcinoma in situ of the breast: a systematic review of incidence, treatment, and outcomes. J Natl Cancer Inst 2010;102:170-178.

4 Harris RE, Beebe-Donk J, Doss H, Burr Doss D: Aspirin, ibuprofen, and other non-steroidal anti-inflammatory drugs in cancer prevention: a critical review of non-selective COX-2 blockade (review). Oncol Rep 2005;13:559-583.
5 Cuzick J, Otto F, Baron JA, et al.: Aspirin and nonsteroidal anti-inflammatory drugs for cancer prevention: an international consensus statement. Lancet Oncol 2009;10:501-507.

6 Elwood PC, Gallagher AM, Duthie GG, et al.: Aspirin, salicylates, and cancer. Lancet 2009;373:1301-1309. 
7 Ulrich CM, Bigler J, Potter JD: Non-steroidal antiinflammatory drugs for cancer prevention: promise, perils and pharmacogenetics. Nat Rev Cancer 2006;6: 130-140.

8 Gonzalez-Perez A, Garcia Rodriguez LA, LopezRidaura R: Effects of non-steroidal anti-inflammatory drugs on cancer sites other than the colon and rectum: a meta-analysis. BMC Cancer 2003;3:28.

9 Moysich KB, Beehler GP, Zirpoli G, et al.: Use of common medications and breast cancer risk. Cancer Epidemiol Biomarkers Prev 2008;17:1564-1595.

10 Khuder SA, Mutgi AB: Breast cancer and NSAID use: a meta-analysis. Br J Cancer 2001;84:1188-1192.

11 Mangiapane S, Blettner M, Schlattmann P: Aspirin use and breast cancer risk: a meta-analysis and meta-regression of observational studies from 2001 to 2005 . Pharmacoepidemiol Drug Saf 2008;17:115-124.

12 Takkouche B, Regueira-Mendez C, Etminan M: Breast cancer and use of nonsteroidal anti-inflammatory drugs: a meta-analysis. J Natl Cancer Inst 2008; 100: 1439-1447.

13 Zhao YS, Zhu S, Li XW, et al.: Association between NSAIDs use and breast cancer risk: a systematic review and meta-analysis. Breast Cancer Res Treat 2009;117: 141-150.

14 Marshall SF, Bernstein L, Anton-Culver H, et al.: Nonsteroidal anti-inflammatory drug use and breast cancer risk by stage and hormone receptor status. J Natl Cancer Inst 2005;97:805-812.

15 Bardia A, Ebbert JO, Vierkant RA, et al.: Association of aspirin and nonaspirin nonsteroidal anti-inflammatory drugs with cancer incidence and mortality. J Natl Cancer Inst 2007;99:881-889.

16 Eliassen AH, Chen WY, Spiegelman D, et al.: Use of aspirin, other nonsteroidal anti-inflammatory drugs, and acetaminophen and risk of breast cancer among premenopausal women in the Nurses' Health Study II. Arch Intern Med 2009;169:115-121.

17 Friis S, Thomassen L, Sorensen HT, et al.: Nonsteroidal anti-inflammatory drug use and breast cancer risk: a Danish cohort study. Eur J Cancer Prev 2008;17:8896.

18 Egan KM, Stampfer MJ, Giovannucci E, et al.: Prospective study of regular aspirin use and the risk of breast cancer. J Natl Cancer Inst 1996;88:988-993.

19 Gierach GL, Lacey JV Jr, Schatzkin A, et al.: Nonsteroidal anti-inflammatory drugs and breast cancer risk in the National Institutes of Health-AARP Diet and Health Study. Breast Cancer Res 2008;10:R38.

20 Jacobs EJ, Thun MJ, Connell CJ, et al.: Aspirin and other nonsteroidal anti-inflammatory drugs and breast cancer incidence in a large U.S. cohort. Cancer Epidemiol Biomarkers Prev 2005;14:261-264.

21 Garcia Rodriguez LA, Gonzalez-Perez A: Risk of breast cancer among users of aspirin and other anti-inflammatory drugs. Br J Cancer 2004;91:525-529.

22 Gill JK, Maskarinec G, Wilkens LR, et al.: Nonsteroidal antiinflammatory drugs and breast cancer risk: the multiethnic cohort. Am J Epidemiol 2007;166:11501158.

23 Meier CR, Schmitz S, Jick H: Association between acetaminophen or nonsteroidal antiinflammatory drugs and risk of developing ovarian, breast, or colon cancer. Pharmacotherapy 2002;22:303-309.

24 Davis S, Mirick DK: Medication use and the risk of breast cancer. Eur J Epidemiol 2007;22:319-325

25 Cronin-Fenton DP, Pedersen L, Lash TL, et al.: Prescriptions for selective cyclooxygenase- 2 inhibitors, non-selective non-steroidal anti-inflammatory drugs, and risk of breast cancer in a population-based casecontrol study. Breast Cancer Res 2010;12:R15.
26 Gates MA, Tworoger SS, Eliassen AH, et al.: Analgesic use and sex steroid hormone concentrations in postmenopausal women. Cancer Epidemiol Biomarkers Prev 2010;19:1033-1041.

27 Key T, Appleby P, Barnes I, et al.: Endogenous sex hormones and breast cancer in postmenopausal women: reanalysis of nine prospective studies. J Natl Cancer Inst 2002;94:606-616.

28 Bosco JL, Palmer JR, Boggs DA, et al.: Regular aspirin use and breast cancer risk in US Black women. Cancer Causes Control 2011;22:1553-1561.

29 Diaz-Cruz ES, Shapiro CL, Brueggemeier RW: Cyclooxygenase inhibitors suppress aromatase expression and activity in breast cancer cells. J Clin Endocrinol Metab 2005;90:2563-2570.

30 Brueggemeier RW, Diaz-Cruz ES: Relationship between aromatase and cyclooxygenases in breast cancer: potential for new therapeutic approaches. Minerva Endocrinol 2006;31:13-26.

31 Brasky TM, Bonner MR, Moysich KB, et al.: Non-steroidal anti-inflammatory drugs (NSAIDs) and breast cancer risk: differences by molecular subtype. Cancer Causes Control 2011;22:965-975.

32 Brueggemeier RW, Diaz-Cruz ES, Li PK, et al.: Translational studies on aromatase, cyclooxygenases, and enzyme inhibitors in breast cancer. J Steroid Biochem Mol Biol 2005;95:129-136.

33 Dannenberg AJ, Altorki NK, Boyle JO, et al.: Cyclooxygenase 2: a pharmacological target for the prevention of cancer. Lancet Oncol 2001;2:544-551.

34 Tinsley HN, Gary BD, Keeton AB, et al.: Sulindac sulfide selectively inhibits growth and induces apoptosis of human breast tumor cells by phosphodiesterase 5 inhibition, elevation of cyclic GMP, and activation of protein kinase G. Mol Cancer Ther 2009;8:3331-3340.

35 Tinsley HN, Gary BD, Keeton AB, et al.: Inhibition of PDE5 by sulindac sulfide selectively induces apoptosis and attenuates oncogenic Wnt/beta-catenin-mediated transcription in human breast tumor cells. Cancer Prev Res (Phila) 2011;4:1275-1284.

36 Thompson HJ, Jiang C, Lu J, et al.: Sulfone metabolite of sulindac inhibits mammary carcinogenesis. Cancer Res 1997;57:267-271.

37 Nakopoulou L, Mylona E, Papadaki I, et al.: Overexpression of cyclooxygenase- 2 is associated with a favorable prognostic phenotype in breast carcinoma. Pathobiology 2005;72:241-249.

38 Ristimaki A, Sivula A, Lundin J, et al.: Prognostic significance of elevated cyclooxygenase- 2 expression in breast cancer. Cancer Res 2002;62:632-635.

39 Subbaramaiah K, Howe LR, Port ER, et al.: HER-2/neu status is a determinant of mammary aromatase activity in vivo: evidence for a cyclooxygenase-2-dependent mechanism. Cancer Res 2006;66:5504-5511.

40 Benoit V, Relic B, Leval Xd Xd, et al.: Regulation of HER-2 oncogene expression by cyclooxygenase- 2 and prostaglandin E2. Oncogene 2004;23:1631-1635.

41 Benoit V, de Moraes E, Dar NA, et al.: Transcriptional activation of cyclooxygenase-2 by tumor suppressor p53 requires nuclear factor-kappaB. Oncogene 2006; 25:5708-5718.

42 Cho MH, Yoon JH, Jaegal YJ, et al.: Expression of cyclooxygenase- 2 in breast carcinogenesis and its relation to HER-2/neu and $\mathrm{p} 53$ protein expression in invasive ductal carcinoma. Breast 2006;15:390-398.

43 Retsky M, Demicheli R, Hrushesky WJ, et al.: Reduction of breast cancer relapses with perioperative nonsteroidal anti-inflammatory drugs: new findings and a review. Curr Med Chem 2013;20:4163-4176.

44 Brasky TM, Bonner MR, Moysich KB, et al.: Non-steroidal anti-inflammatory drug (NSAID) use and breast cancer risk in the Western New York Exposures and Breast Cancer (WEB) Study. Cancer Causes Control 2010;21:1503-1512.
45 Harris RE, Chlebowski RT, Jackson RD, et al.: Breast cancer and nonsteroidal anti-inflammatory drugs: prospective results from the Women's Health Initiative. Cancer Res 2003;63:6096-6101.

46 Kwan ML, Habel LA, Slattery ML, Caan B: NSAIDs and breast cancer recurrence in a prospective cohort study. Cancer Causes Control 2007;18:613-620.

47 Forget P, Vandenhende J, Berliere M, et al.: Do intraoperative analgesics influence breast cancer recurrence after mastectomy? A retrospective analysis. Anesth Analg 2010;110:1630-1635.

48 Li Y, Brasky TM, Nie J, et al.: Use of nonsteroidal antiinflammatory drugs and survival following breast cancer diagnosis. Cancer Epidemiol Biomarkers Prev 2012;21:239-242.

49 Wernli KJ, Hampton JM, Trentham-Dietz A, Newcomb PA: Use of antidepressants and NSAIDs in relation to mortality in long-term breast cancer survivors. Pharmacoepidemiol Drug Saf 2011;20:131-137.

50 Blair CK, Sweeney C, Anderson KE, Folsom AR: NSAID use and survival after breast cancer diagnosis in post-menopausal women. Breast Cancer Res Treat 2007;101:191-197.

51 Holmes MD, Chen WY, Li L, et al.: Aspirin intake and survival after breast cancer. J Clin Oncol 2010;28: 1467-1472.

52 Holmes MD, Olsson H, Pawitan Y, et al.: Aspirin intake and breast cancer survival - a nation-wide study using prospectively recorded data in Sweden. BMC Cancer 2014;14:391.

53 Sharpe CR, Collet JP, McNutt M, et al.: Nested casecontrol study of the effects of non-steroidal anti-inflammatory drugs on breast cancer risk and stage. Br J Cancer 2000;83:112-120.

54 Terry MB, Gammon MD, Zhang FF, et al.: Association of frequency and duration of aspirin use and hormone receptor status with breast cancer risk. JAMA 2004; 291:2433-2440.

55 Rahme E, Ghosn J, Dasgupta K, et al.: Association between frequent use of nonsteroidal anti-inflammatory drugs and breast cancer. BMC Cancer 2005;5:159.

56 Zhang Y, Coogan PF, Palmer JR, et al.: Use of nonsteroidal antiinflammatory drugs and risk of breast cancer: the Case-Control Surveillance Study revisited. Am J Epidemiol 2005;162:165-170.

57 Kirsh VA, Kreiger N, Cotterchio M, et al.: Nonsteroidal antiinflammatory drug use and breast cancer risk: subgroup findings. Am J Epidemiol 2007;166:709-716.

58 Gallicchio L, Visvanathan K, Burke A, et al.: Nonsteroidal anti-inflammatory drugs and the risk of developing breast cancer in a population-based prospective cohort study in Washington County, MD. Int J Cancer 2007;121:211-215.

59 Langman MJ, Cheng KK, Gilman EA, et al.: Effect of anti-inflammatory drugs on overall risk of common cancer: case-control study in general practice research database. BMJ 2000;320:1642-1646.

60 Ready A, Velicer CM, McTiernan A, et al.: NSAID use and breast cancer risk in the VITAL cohort. Breast Cancer Res Treat 2008;109:533-543.

61 Hanf V, Schütz F, Liedtke C, Thill M; on behalf of the AGO Breast Committee: AGO Recommendations for the Diagnosis and Treatment of Patients with Early Breast Cancer: Update 2015. Breast Care 2015;10:189197.

62 Liedtke C, Thill M, Hanf V, Schütz F; on behalf of the AGO Breast Committee: AGO Recommendations for the Diagnosis and Treatment of Patients with Advanced and Metastatic Breast Cancer: Update 2015. Breast Care 2015;10:199-205. 